\title{
EDITORIAL
}

\section{Relicensing, recertification and regulation}

\author{
Graeme Catto
}

\begin{abstract}
Proposed changes to the regulation of healthcare professionals in the UK set regulators a considerable challenge. Here I examine the nature of the challenge and what the General Medical Council (GMC) and its partners are doing to meet it. Relicensing and recertification are crucial. Revalidation is the sum of their parts and the duty of any responsible regulator. Effective revalidation will provide affirmation of doctors' entitlement to practise, and give the public the assurance that the doctors who treat them are up to date and fit to practise. The GMC's Good Medical Practice is central to any new system, and I outline the GMC's long-term thinking and immediate priorities, including the development of colleague and patient questionnaires and plans to introduce licences to practise.
\end{abstract}

The recent government White Paper on the regulation of healthcare professionals in the UK (Secretary of State for Health, 2007) set regulators a considerable challenge. Relicensing and recertification lie at the heart of that challenge. Revalidation - the sum of their parts - is surely the duty of any responsible regulator; and it is vital that we get it right. If we do, the package will provide a positive affirmation of a doctor's entitlement to practise, and give the public the assurance owed them that the doctors who treat them are up to date and competent.

The General Medical Council (GMC) is committed to the reform and modernisation of the way medicine is regulated in the UK. It believes in a system of medical regulation that fosters the delivery of safe, high-quality care for patients, is based on clear standards that are fair, transparent and open, is properly coordinated across the different organisations involved in all four UK countries, is both independent and accountable and, above all, can command the support and confidence of patients, the public and doctors.

\section{GMC reform programme}

One of the GMC's core functions is the setting of professional standards, and the new version of Good Medical Practice (General Medical Council, 2006) will be central to the development of relicensing and recertification. The medical Royal Colleges have already done valuable work on elaborating the principles of Good Medical Practice for their specialties.

\section{Revalidation}

The regulatory system currently in force involves revalidation, the periodic renewal of doctors' registration, ensuring that they remain up to date and fit to practise. The 2007 White Paper proposes a revised revalidation system with two core components: (a) relicensing (the equivalent of the current revalidation) and (b) specialist and general practitioner recertification. For all doctors in the UK, the GMC will issue licences to practise, which will normally need to be renewed every 5 years. Evidence from the relicensing and recertification processes will feed into the doctor's revalidation by the GMC (Fig. 1).

\section{Relicensing}

Relicensing (sometimes called 'relicensure') will apply to all licensed doctors. It will be based on agreed generic standards of practice set by the GMC, a revised system of National Health Service (NHS) appraisal for doctors and certification of suitability for relicensing - providing confirmation that any issues about the doctor's practice have been resolved - by the relevant medical director. Doctors will need to engage satisfactorily in an annual appraisal, and participate in 'workplace $360^{\circ}$

Graeme Catto is President of the General Medical Council (Regent's Place, 350 Euston Road, London NW1 3JN, UK. Email: g.catto@abdn. ac.uk) and Professor of Medicine, University of Aberdeen. Until 2005, he was Vice-Principal at King's College London, Dean of the Guy's, King's College and St Thomas' Hospitals' Medical and Dental School and Pro-Vice Chancellor, University of London. Formerly Chief Scientist at the Scottish Executive Health Department, he is currently a member of the Council for Healthcare Regulatory Excellence, Governor of the Science Technology Park in Qatar and Chair of the Scottish Centre for Regenerative Medicine. 


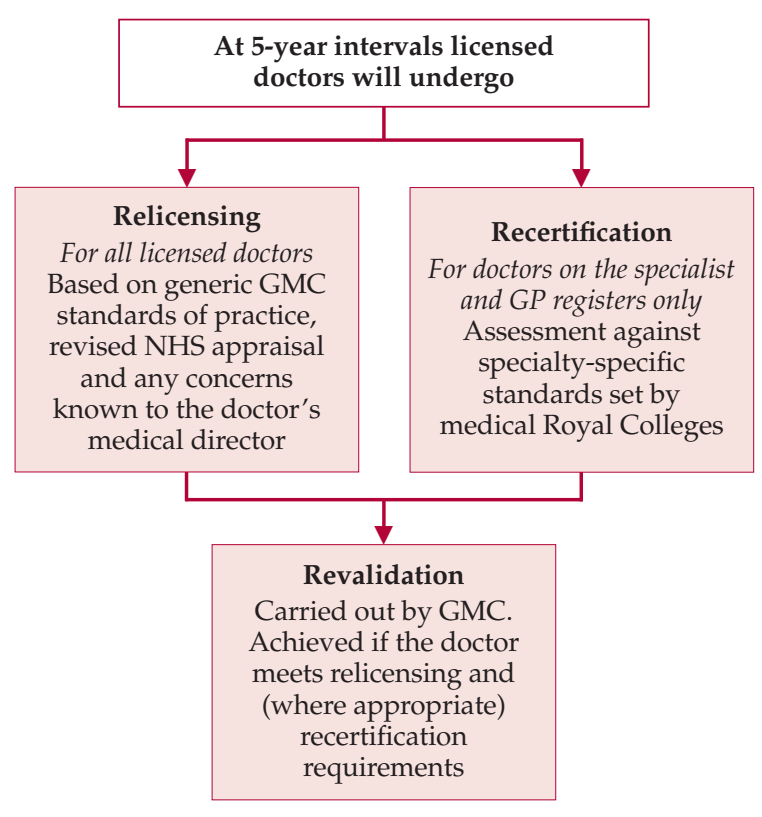

Fig. 1 The proposed regulatory system.

multisource feedback' - where colleagues and others give their views on the doctor's performance.

\section{Recertification}

Recertification will apply only to doctors who are on the specialist or general practitioner (GP) register. They will need to demonstrate that they continue to meet the standards that apply to their specialty. The medical Royal Colleges ${ }^{\dagger}$ will lead this process - a comprehensive assessment against standards drawn up by each College - and will deliver to the GMC a statement of assurance about each doctor's practice.

The GMC will need to be satisfied that College processes are sufficient to provide assurance of the integrity of the specialist and GP registers. The Department of Health in England has provided funding to the Academy of Medical Royal Colleges (AMRC) to support the development of recertification processes and has asked the Academy, working closely with the GMC, to establish a UK working group to support coordination and piloting.

\section{Moving forward}

The GMC is committed to making progress where it can as rapidly as it can, and much useful work is already well under way. For example, it has for

${ }^{+}$An editorial by Laurence Mynors-Wallis, Associate Dean of the Royal College of Psychiatrists and lead for revalidation, will appear in the next issue of APT. Ed. some time been developing colleague and patient questionnaires for doctors to use to gather feedback on their practice. Teams at Peninsula Medical School (UK) and the Client-Focused Evaluations Programme have now completed a more extensive pilot study to determine, among other things, the questionnaires' basic psychometric properties and how they can best be administered. Initial results are very encouraging.

Meanwhile, the AMRC has undertaken important work both on guidance for practising doctors on the evidence they will need for revalidation, and on the consistency and effectiveness of CPD. It has now commissioned an academic study to evaluate the way CPD can contribute evidence to support revalidation. The project will be delivered through a partnership between the College of Emergency Medicine and Manchester Metropolitan University.

The GMC is keen to do more, and an immediate priority is to introduce licences to practise as soon as practicable. A good regulator should know the population it seeks to regulate; and as part of the GMC's preparation for issuing licences it needs to collect additional information about registered doctors - such as information about their practice. These data will underpin the GMC's risk-based approach to regulation, including revalidation. This helps it to target its resources where local regulatory systems do not exist or are not effective and to avoid unnecessary burden, overlap and duplication of effort - especially for doctors.

But the GMC cannot act alone. The medical Royal Colleges have a vital part to play, and the NHS and other healthcare providers need to ensure that they have appropriate systems in place before the GMC can implement an effective system of revalidation. The GMC needs, too, the help and cooperation of the broader profession if it is to succeed.

It is vital for the future of the profession that we all get revalidation right. The GMC looks forward to working with all of its partners to deliver this crucial stage in the development of medical regulation. There is a real opportunity to create a framework, and a regulatory system, that commands the confidence of all who receive and provide healthcare in the UK - with patient safety at its heart.

\section{Declaration of interest}

\author{
G.C. is President of the General Medical Council.
}

\section{References}

General Medical Council (2006) Good Medical Practice. GMC. Secretary of State for Health (2007) Trust, Assurance and Safety The Regulation of Health Professionals in the 21st Century. TSO (The Stationery Office). http://www.official-documents.gov. uk/document/cm70/7013/7013.pdf 